\title{
Astragaloside IV Prevents Cardiac Remodeling in the Apolipoprotein E-Deficient Mice by Regulating Cardiac Homeostasis and Oxidative Stress
}

\author{
Xiong-Zhi Lia, c Yan-Zi Ding ${ }^{a}$ Heng-Fang Wu ${ }^{b}$ Zhi-Ping Bian ${ }^{a}$ Jin-Dan Xu ${ }^{b}$ \\ Chun-Rong Gu ${ }^{a}$ Xiang-Jian Chen ${ }^{\mathrm{a}}$ Di Yang $^{\mathrm{b}}$
}

aResearch Institute of Cardiovascular Disease, ${ }^{b}$ Department of Cardiology, The First Affiliated Hospital of Nanjing Medical University, Nanjing, 'Cardiovascular Department in the Central Hospital of ShaoYang, ShaoYang, Hunan, China

\section{Key Words}

Hypercholesterolemia • Astragaloside IV • Cardiac remodeling $\bullet$ Tissue homeostasis $•$ Oxidative stress

\begin{abstract}
Background: Hypercholesterolemia is a risk factor for the development of cardiac hypertrophy. Astragaloside IV (AST-IV) possesses cardiovascular protective properties. We hypothesize that AST-IV prevents cardiac remodeling with hypercholesterolemia via modulating tissue homeostasis and alleviating oxidative stress. Methods: The ApoE $\mathrm{E}^{-/-}$mice were treated with AST-IV at 1 or $10 \mathrm{mg} / \mathrm{kg}$ for 8 weeks. The blood lipids tests, echocardiography, and TUNEL were performed. The mRNA expression profile was detected by real-time PCR. The myocytes size and number, and the expressions of proliferation (ki67), senescence ( $\mathrm{p} 16^{\text {INK4a }}$ ), oxidant (NADPH oxidase 4, NOX4) and antioxidant (superoxide dismutase, SOD) were observed by immunofluorescence staining. Results: Neither $1 \mathrm{mg} / \mathrm{kg}$ nor $10 \mathrm{mg} / \mathrm{kg}$ AST-IV treatment could decrease blood lipids in $\mathrm{ApoE}^{-/-}$mice. However, the decreased left ventricular ejection fraction (LVEF) and fractional shortening (FS) in $\mathrm{ApoE}^{-/-}$mice were significantly improved after AST-IV treatment. The cardiac collagen volume fraction declined nearly in half after AST-IV treatment. The enlarged myocyte size was suppressed, and myocyte number was recovered, and the alterations of genes expressions linked to cell cycle, proliferation, senescence, p53apoptosis pathway and oxidant-antioxidants in the hearts of $\mathrm{ApoE}^{-/-}$mice were reversed after AST-IV treatment. The decreased ki67 and increased $\mathrm{p} 16^{\mathrm{INK} 4 \mathrm{a}}$ in the hearts of $\mathrm{ApoE}^{-/-}$mice were recovered after AST-IV treatment. The percentages of apoptotic myocytes and NOX4-positive cells in AST-IV treated mice were decreased, which were consistent with the gene expressions. Conclusion: AST-IV treatment could prevent cardiac remodeling and recover the impaired ventricular function induced by hypercholesterolemia. The beneficial effect of AST-IV might partly be through regulating cardiac homeostasis and anti-oxidative stress.

X.-Z. Li and Y.-Z. Ding contributed equally to this work.




\section{Cellular Physiology Cell Physiol Biochem 2017;44:2422-2438

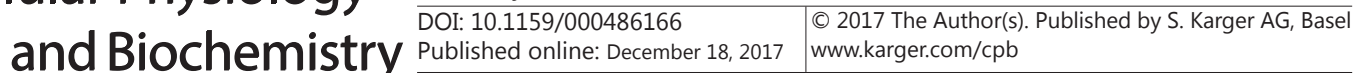 \\ Li et al.: Astragaloside IV Prevents Cardiac Remodeling in $\mathrm{ApoE}^{-1-}$ Mice}

\section{Introduction}

Cardiac hypertrophy is generally recognized as an adaptive response of the myocardium to various intrinsic and extrinsic stimuli, which lead the heart to work harder during conditions of increased workload. Cardiac myocytes initially expand in size and increase their protein synthesis, which result in increasing muscle mass. However, prolonged cardiac hypertrophy causes myocyte disarray, apoptosis and interstitial fibrosis, which cease its compensatory function. Eventually, the myocardial remodeling progresses to ventricular dilatation and heart failure [1, 2], which is one of the leading causes of mortality in the world. Hypercholesterolemia is regarded as a major risk factor for atherosclerosis and heart disease, and increases all-cause mortality in different epidemiological studies [3-5]. But little is known regarding the direct effects of hypercholesterolemia on cardiac hypertrophy. Previous prospective longitudinal cohort study showed that hypercholesterolemia, as well as hypertension and obesity, predicted the prevalence of left ventricular (LV) hypertrophy twenty years later in human [6, 7]. Hypercholesterolemia in normotensive, non-diabetic adults was independently associated with mild, concentric LV geometry [7]. Therefore, these clinic studies suggested that hypercholesterolemia played a role in the origin of myocardial remodeling.

The apolipoprotein E-deficient $\left(\mathrm{ApoE}^{-/-}\right)$mouse has been the most widely used animal model for hyperlipidemia and atherosclerosis because it has substantially increased total plasma cholesterol, i.e. hypercholesterolemia, and rapidly develops atherosclerotic lesions similar to those noted in humans [8]. Apart from the obvious vascular phenotype in the Apo $\mathrm{E}^{-/-}$mouse, the cardiac phenotypes, such as cardiac hypertrophy [1, 2, 9-12], fibrosis [2, 8] and dysfunction, were also noticed, but not intensively investigated. Besides the ApoE ${ }^{-/}$ animal model, the study in swine fed a high caloric diet suggested that oxidized cholesterols was closely related to cardiac hypertrophy, dysfunction, and increased epicardial fat thickness [13]. High-cholesterol-fed rabbits presented "cholesterol cardiomyopathy" characterized by systolic and diastolic dysfunction [14]. Cholesterol loading to H9c2 cells induced hypertrophic characteristic features, such as increase in cellular surface area and up-regulated expression of hypertrophic gene markers [15]. More studies have provided evidence that hypercholesterolemia is associated with cardiac hypertrophy, which appears to be influenced by several factors, including increased aortic stiffness, arterial hypertension, age, and a Western-type diet. The precise mechanisms leading to cardiac hypertrophy in the hypercholesterolemia are not clear. There exists substantial evidence demonstrating that hypercholesterolemia induces oxidative and/or nitrative stress in the heart, and in turn oxidative and/or nitrative stress plays a role in several cardiac pathologies in hypercholesterolemia [16].

The heart constantly renews itself, and a balance between cardiac cell death and regeneration preserves suitable myocyte number, and keeps tissue homeostasis [17]. Cell regeneration, the proliferative activity of cardiomyocytes, is the basis of the heart providing its structural integrity and functional activity [18-21]. Almost all types of heart disease are based on the cardiomyocytes deficiency, which is caused by lower cell regeneration and/or higher cell death (e.g. necrosis, apoptosis). The damaged cells cannot be replaced by new ones and repaired by scar formation and fibrosis. The survival cardiomyocytes continue to grow mainly by hypertrophy, that is an increase in cell size. Little is known about the detrimental effects of hypercholesterolemia on cardiomyocyte number, size and tissue homeostasis, including myocyte regeneration, senescence and apoptosis.

Astragaloside IV (AST-IV, 3-0- $\beta$-D-xylopyranosyl-6-O- $\beta$-D-glucopyranosylcycloastragenol), is a monomeric and natural saponin isolated from Astragalusmembranaceus (Fisch.) $B g e$, which is a traditional Chinese herb widely used in clinical practice and has been demonstrated to be effective in treating various diseases $[22,23]$, including cardiovascular diseases $[24,25]$. AST-IV possesses diverse cardiovascular protective properties against cardiac hypertrophy [26-30], cardiomyocyte apoptosis [29-33], myocardial fibrosis [30, 34-36], oxidative stress [31,37] and so on. 


\section{Cellular Physiology Cell Physiol Biochem 2017;44:2422-2438 \begin{tabular}{l|l|l}
\hline and Biochemistry $10.1159 / 000486166$ & $\begin{array}{l}\text { C) } 2017 \text { The Author(s). Published by S. Karger AG, Basel } \\
\text { www.karger.com/cpb }\end{array}$ \\
\hline
\end{tabular}}

In this study, we studied the changes of cardiac remodeling in hypercholesterolemic ApoE $\mathrm{E}^{-/-}$mice treated with AST-IV. The states of cardiac homeostasis, including myocyte regeneration, senescence and apoptosis, and the heart oxidative stress were investigated.

\section{Materials and Methods}

\section{Astragaloside IV (AST-IV) preparation}

AST-IV was purchased from Spring \& Autumn Biological Engineering Co., Ltd. (Nanjing, Jiangsu, China), and its purity was shown to be $>98 \%$ by high-performance liquid chromatography (HPLC) analysis and thin layer chromatography (TLC) with a single dot. AST-IV was completely dissolved in hydroxypropyl-betacyclodextrin (HPBCD; Sigma, St. Louis, MO, USA) to obtain solutions at concentrations of $0.1 \mathrm{mg} / \mathrm{ml}$ and 1 $\mathrm{mg} / \mathrm{ml}$, respectively.

\section{Animals}

Male $\mathrm{ApoE}^{-/-}$mice (body weight $18 \pm 2 \mathrm{~g}$ ) at 6-7 weeks of age used in this experiment were purchased from Cavens Lab Animal Co., Ltd. (Changzhou, Jiangsu, China) and housed at Medical Animal Experimental Base of Jiangsu Province. The age-matched and gender-matched genetic background C57BL/6J mice (wildtype) were served as control group (WT, $\mathrm{n}=7$ ). All mice were fed with normal diet. The ApoE $\mathrm{E}^{-/-}$mice were divided randomly into 3 groups: model group (KO, $n=7$ ), AST-IV low dose (AST-LD, $n=7$ ) and high dose (AST-HD, $n=8$ ) treatment group. The latter two groups received intraperitoneal injection of $1 \mathrm{mg} / \mathrm{kg}$ and $10 \mathrm{mg} / \mathrm{kg}$ of AST-IV respectively every other day over 8 weeks. At the same time, control and model mice were injected with dissolvent HPBCD in the same volume. At 16 weeks, mice were anesthetized with $1 \%$ pelltobarbitalum natricum $(50 \mathrm{mg} / \mathrm{kg})$ and sacrificed to assess the therapeutic effects of AST-IV. Another WTs $(n=8)$ and KOs $(n=7)$ at the age of 8 weeks were killed after anesthetization to obtain baseline parameters. This study protocol was approved by Medical Ethical Committee of the First Affiliated Hospital of Nanjing Medical University.

\section{Plasma Lipid Levels}

For detection of plasma lipid levels, mice were kept from feeding the chow diet but water for 12 hours. After that, they were weighed, and the plasma was collected with heparin lithium anticoagulant tube. The concentrations of plasma lipid levels including total cholesterol (TC), triglycerides (TG), low density lipoprotein-cholesterol (LDL-C) and high density lipoprotein-cholesterol (HDL-C) were measured by an automatic biochemistry analyzer (Beckman Coulte Olympus, CA, USA).

\section{Echocardiography and Cardiac Anatomy}

Mice were anesthetized with isoflurane (2-3\% induction and $0.5-1.5 \%$ maintenance), and then M-mode echocardiographic parameters of left ventricular (LV) in the short axis view at the level of the papillary muscles were measured by a high resolution Micro-Ultrasound system (Vevo 2100, VisualSonics Inc., Toronto, Ontario, Canada). The results of LV diameter and posterior wall thickness were collected during diastole and systole. The left ventricular ejection fraction (LVEF) and fractional shortening (FS) were calculated. After sacrificing, the heart and LV were dissected and weighed to calculate the LV-to-heart weight ratio. Then, the $\mathrm{LV}$ was sectioned equally into 2 parts perpendicular to the longitudinal axis of the heart, one was embedded in Tissue-Tek ${ }^{\circledR}$ O.C.T compound (Sakura Finetek USA, Inc., Torrance, CA, USA) to obtain frozen sections for histology study, and the other was frozen rapidly in liquid nitrogen and preserved at $-80^{\circ} \mathrm{C}$ until use.

\section{Myocyte Size and Number}

The myocyts size and number were measured according to the method of published papers [17, 38]. Briefly, heart sections were stained with cardiac troponin I (cTnI) antibody (sc-133117, Santa Cruz Biotechnology, Inc., CA, USA) and propidium iodide (PI). Morphometric sampling consisted in counting by confocal microscopy the number of myocyte nuclear profiles in an area of tissue section in which cardiac muscle cells were cut perpendicularly. Endomyocardial and epimyocardial regions of LV were photographed to determine the number of nuclear profiles per unit area of myocardium, N(n)A, and the volume fraction 


\section{Cellular Physiology Cell Physiol Biochem 2017;44:2422-2438 \begin{tabular}{l|l|l} 
and Biochemistry & DOI: 10.1159/000486166 & $\begin{array}{l}\text { C } 2017 \text { The Author(s). Published by S. Karger AG, Basel } \\
\text { www.karger.com/cpb }\end{array}$
\end{tabular}

of myocytes, V(m)V. Nuclear length, D(n), was obtained from measurements in longitudinally oriented myocytes. Number of myocytes per unit volume of myocardium, N(m)V, was calculated from:

$\mathrm{N}(\mathrm{m}) \mathrm{V}=\mathrm{N}(\mathrm{n}) \mathrm{A} / \mathrm{D}(\mathrm{n})$.

Myocyte cell volume, $\mathrm{V}(\mathrm{m})$, was computed from the volume fraction of myocytes in the tissue, $\mathrm{V}(\mathrm{m}) \mathrm{V}$, and the number of myocytes per unit volume of myocardium, $\mathrm{N}(\mathrm{m}) \mathrm{V}$ :

$\mathrm{V}(\mathrm{m})=\mathrm{V}(\mathrm{m}) \mathrm{V} / \mathrm{N}(\mathrm{m}) \mathrm{V}$.

The total number of myocytes in the $\mathrm{LV}, \mathrm{N}(\mathrm{m}) \mathrm{T}$, was derived from the product of the number of myocytes per unit volume, $\mathrm{N}(\mathrm{m}) \mathrm{V}$, and the total $\mathrm{LV}$ volume, VT. The latter was evaluated by dividing ventricular weight by the specific gravity of muscle tissue, $1.06 \mathrm{~g} / \mathrm{cm}^{3}$.

$\mathrm{N}(\mathrm{m}) \mathrm{T}=\mathrm{N}(\mathrm{m}) \mathrm{V} \times \mathrm{VT}$.

\section{Quantitative RT-PCR}

Total RNA was extracted from tissue with RNAiso Plus (Takara Bio, Dalian, China) according to the manufacturer's instructions. Total RNA $(1 \mu \mathrm{g})$ was reverse-transcribed into cDNA using the PrimeScript ${ }^{\mathrm{TM}} \mathrm{RT}^{\mathrm{T}}$ reagent kit (Takara Bio, Dalian, China). Then, the cDNA was amplified using SYBR Premix Ex Taq ${ }^{\text {TM }}$ (Takara Bio, Dalian, China) under the following conditions: 1 cycle of $94^{\circ} \mathrm{C}$ for $30 \mathrm{sec}$, followed by 40 cycles of $94^{\circ} \mathrm{C}$ for $5 \mathrm{sec}, 60^{\circ} \mathrm{C}$ for $30 \mathrm{sec}$ and $72^{\circ} \mathrm{C}$ for $30 \mathrm{sec}$. The primers were synthesized by Sangong Biotech Co., Ltd. (Shanghai, China). All samples were performed in triplicate using a thermal cycler system for nucleic acid amplification (7900, Applied Biosystems, Foster City, CA, USA). The average cycle threshold (Ct) from the triplicate PCRs of the target or internal control gene was calculated first, and then $2^{-\Delta \mathrm{Ct}}$ transformation for individual and the mean $2^{-\Delta \mathrm{Ct}}$ of the control group were obtained. The $2^{-\Delta \Delta \mathrm{Ct}}$ for each sample was calculated by dividing $2^{-\Delta \mathrm{Ct}}$ of individual samples from hypercholesterolemic or AST-IV treated groups by the mean $2^{-\Delta \mathrm{Ct}}$ of the control group [39].

A series of genes related to the cell cycle, proliferation, senescence, p53-dependent apoptosis pathway and oxidants-antioxidants, were tested in this study. The cell cycle regulators at transcriptional level of G1, G1/S transition and G2/M transition were examined, including Cyclin D1, which drives cells from G1 to S, is activated by the cyclin dependent kinase CDK4 [38]. In addition, Cyclin E1 forms a complex with CDK2 and phosphorylates $\mathrm{p} 27^{\mathrm{Kip} 1}$ (an inhibitor of Cyclin D1), tagging it for degradation, thus promoting expression of Cyclin A2, allowing progression to S phase [40]. During G2, the cyclin B1-cdc2 complex, composed by Cyclin B1 and cdc2, is inactivated by phosphorylation [38]. Genes associated with the cyclin dependent kinase inhibitors (CDKIs), such as CDKN1A (p21 $1^{\text {Cip }}$ ), CDKN1B (p27 ${ }^{\text {Kip } 1}$ ) and CDKN2A (p16 ${ }^{\text {INK4a }}$ ), cell proliferation (Ki67, MCM5), and senescence (CDKN2A), were determined. The genes related to p53-dependent apoptosis pathway were examined, including Bax, CDKN1A, TP53, Bcl2 and GADD45A.

\section{Histology and Immunofluorescence Staining}

Frozen sections, $8 \mu \mathrm{m}$ in thickness, were used for immunolabeling. Masson trichrome staining was performed according to standard protocol to determine fibrosis of the LV. Myocytes were labeled by cTnI mouse monoclonal antibody with a M.O.M. immunodetection kit (BMK-2202, Vector Laboratories, Burlingame, CA, USA). Oxidative stress and anti-oxidative stress effects were determined by NADPH oxidase 4 (NOX4, ab133303, Abcam, Cambridge, UK), superoxide dismutase 1 (SOD1, ab13498, Abcam, Cambridge, UK) and superoxide dismutase 2 (SOD2, ab13533, Abcam, Cambridge, UK) staining, respectively. Cycling cells were marked by Ki67 (ab16667, Abcam, Cambridge, UK). To test cellular senescence, sections were exposed to P16 ${ }^{\mathrm{INK} 4 \mathrm{a}}$ antibodies (ab108349, Abcam, Cambridge, UK). Alexa Fluor ${ }^{\circledR} 594$ and 488 conjugated secondary antibodies from Life Technologies (A21207 and A21208, Carlsbad, CA, USA) were used to combine with the above-mentioned primary antibodies, respectively. DAPI (H-1200, Vector Laboratories, Burlingame, CA, USA) was used to identify the nuclei. All positive staining cells were counted on 5 nonoverlapping but serial regions from inner layer to outer layer of each LV free wall ( $\times 200$ magnification).

In Situ Terminal Deoxynucleotidyl Transferase Mediated dUTP Nick End Labeling (TUNEL) In situ cell death detection kit (No.11684795910, Roche Applied Science, Branford, CT, USA) with fluorescein was employed and performed principally according to the manufacturer's instructions to detect and quantify apoptosis at single cell level based on labeling of DNA stand breaks. All positive staining cells were counted on 5 non-overlapping but serial regions from inner layer to outer layer of each LV free wall $(\times 200$ magnification). 
Data Analysis and Statistics.

Continuous variables were presented as mean \pm SD. The relative change of two groups (including a reference group) is expressed as a percentage of the difference between the values of two groups divided by the value of reference group. Significance between two groups was conducted by Student's t-test. The analysis of variance (ANOVA) and Dunnett's test were employed in multiple comparisons. The chi-square test was used to compare categorical variables. All analyses were managed with SPSS 22.0, and P $<0.05$ was considered statistically significant.

\section{Results}

AST-IV treatment didn't decrease plasma lipid levels of ApoE ${ }^{-/-}$mouse

In accord with previous reports [1], ApoE $\mathrm{E}^{-/-}$mouse displayed severe hypercholesterolemia rather than hypertriglyceridemia at 8 weeks of age. The concentrations of TC and LDL-C in KOs were 3.7-fold and 8.7-fold higher, respectively, than those of WTs (Fig. 1A-B). Conversely, HDL-C level decreased $23 \%$ compared with that of WTs. No significant difference in TG between the two groups was detected (Fig. 1C-D). The four plasma lipid levels in KOs reduced from 8 weeks to 16 weeks of age, but TC and LDL-C levels were still significantly higher than those of WTs. HDL-C was significantly lower than that of WTs $(\mathrm{P}<0.05)$. The great variability in the cholesterol levels of $\mathrm{ApoE}^{-/-}$mice with chow diet or Western diet aged from 6 weeks to 40 weeks was also reported previously [8]. After administrated with AST-IV for 8 weeks, the mice in AST-LD and AST-HD groups showed higher plasma TC and LDL-C in comparison with the KOs (Fig. 1A-B). HDL-C was increased 1.9 times in AST-LD group, compared with that of KOs $(\mathrm{P}<0.05)$. Overall, $\mathrm{ApoE}^{-/-}$mice developed hypercholesterolemia, and treatment with AST-IV for 8 weeks could not decrease the TC and LDL-C levels of ApoE ${ }^{-/-}$mice. $^{2}$

AST-IV treatment could reduce cardiac mass and size, improve cardiac function of ApoE $E^{-/-}$ mice

At 8 weeks of age, heart weight (HW), left ventricular weight (LVW), heart-to-body weight ratio (HW/BW), LVW-to-BW ratio (LVW/BW), and LVW-to-HW ratio (LVW/HW) increased in KOs mice (Fig. 2A-E). Meanwhile, LV longitudinal axis (LAX) increased consistently (Fig. 2F), resulting in a significant expansion of LV. Besides, differences of these variables became even greater in HW, HW/BW, LAX at 16 weeks of age. All these parameters in AST-HD mice were

Fig. 1. AST-IV treatment didn't decrease plasma lipid levels of $\mathrm{ApoE}^{-/-}$ mice. TC (A), LDL-C (B), HDL-C (C), and TG (D). Values shown are mean \pm SD. Student's t-test was used to compare the means of two groups at 8W. ANOVA and Dunnett's test were employed in multiple comparisons at $16 \mathrm{~W} .{ }^{*}, \mathrm{P}<0.05$ vs. WT at 8 or 16 weeks of age (8W or $16 \mathrm{~W}$ ); \#, P $<0.05$ vs. KO at 16 weeks of age.

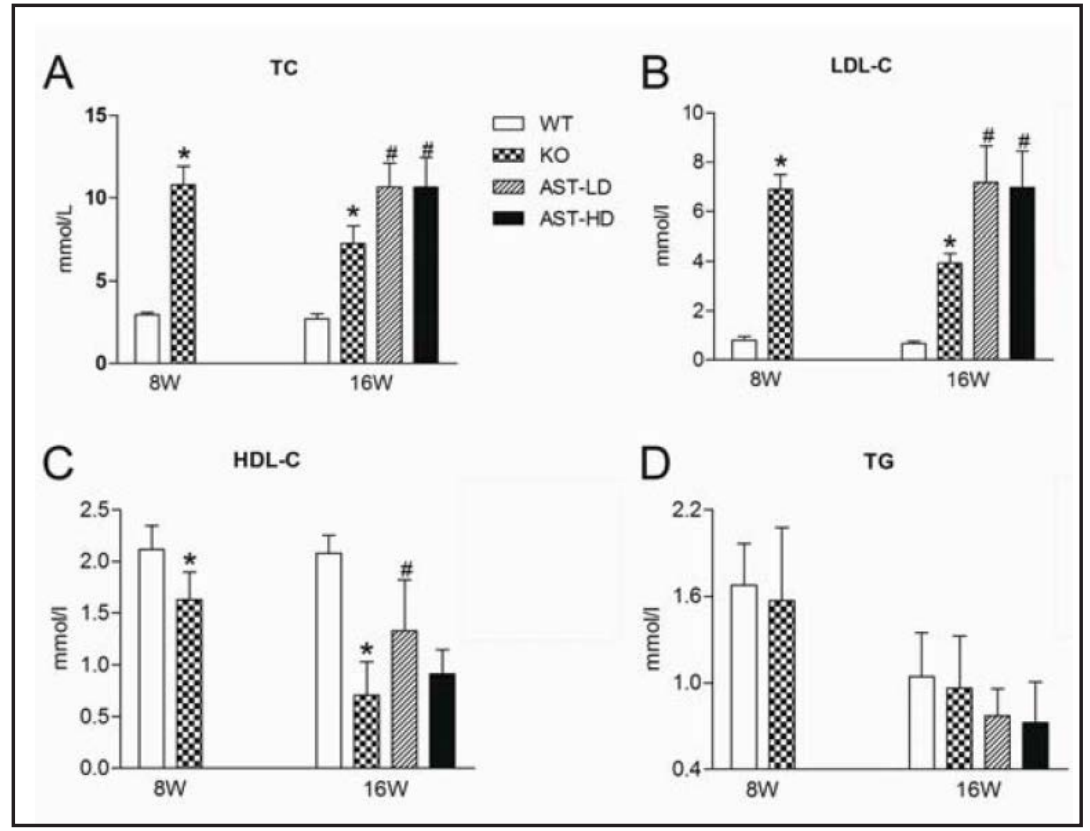




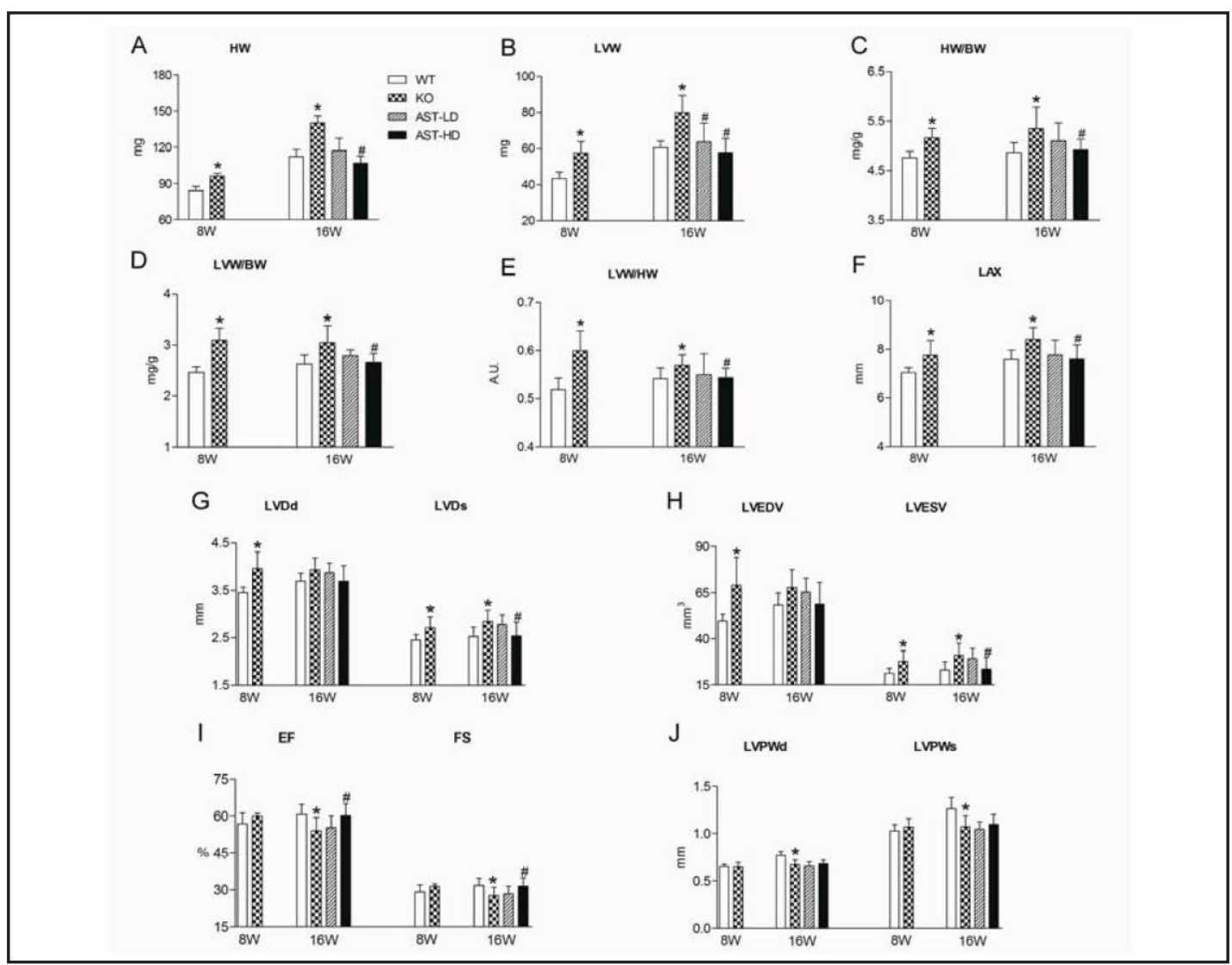

Fig. 2. AST-IV treatment could reduce cardiac mass, size and improve cardiac function of $\mathrm{ApoE}^{-/-}$mice. A, HW; B, LVW; C, HW/BW; D, LVW/BW; E, LVW/HW; F, Longitudinal axis; G, LVDd and LVDs; H, LVEDV and LVESV; I, LVEF and FS; J, LVPWd and LVPWs. Values shown are mean \pm SD. Student's t-test was used to compare the means of two groups at 8W. ANOVA and Dunnett's test were employed in multiple comparisons at $16 \mathrm{~W} .{ }^{*}, \mathrm{P}<0.05$ vs. WT mice at 8 or 16 weeks of age ( $8 \mathrm{~W}$ or $\left.16 \mathrm{~W}\right) ; \#, \mathrm{P}<0.05$ vs. KO animals at 16 weeks of age.

reduced (HW 24\%, LVW 28\%, HW/BW 8\%, LVW/BW 10\%, LVW/HW 5\%, LAX 10\%), and were not altered in AST-LD except a 20\% decrease in LVW, compared with KOs.

Echocardiographic measurements responded to the changes of cardiac weights, size and function. At 8 weeks of age, compared with WTs, the increase of left ventricular enddiastolic dimension (LVDd, 14\%) and left ventricular end-systolic dimension (LVDs, 11\%) (Fig. 2G), in combination with the growth of LAX, resulted in an increase in left ventricular end-diastolic volume (LVEDV, 39\%) and left ventricular end-systolic volume (LVESV, 30\%), respectively (Fig. 2H), in KOs with hypercholesterolemia. At 16 weeks of age, besides the increase of LVDs and LAX, KOs had the characteristics of a 35\% rise in LVESV, and importantly, a decrease in LVEF (11\%), FS (13\%) (Fig. 2I), left ventricular posterior wall at end systole (LVPWs, 6\%), and left ventricular posterior wall at end diastole (LVPWd, 13\%), compared with WTs (Fig. 2J). Taken together, the LV size expansion and systolic function injury suggested adverse cardiac remodeling in KOs with hypercholesterolemia. No alteration of parameters of heart function was observed in WTs mice treated with AST-IV for 8 weeks (Data not shown). In contrast, the changes of LVEF and FS in AST-HD treated ApoE $/$ - were significantly improved (LVEF: $60 \% \pm 4.89 \%$ vs. $54 \% \pm 5.16 \%$; FS: $31 \% \pm 3.36 \%$ vs. $28 \% \pm 3.39 \%$ ) in comparison with those of KOs. Simultaneously, the decrease of LVDs (11\%) and LAX led to a restore in LVESV. No significant improvement in echocardiographic measurements was detected in AST-LD at 16 weeks compared with KOs. 
Fig. 3. AST-IV treatment could decrease cardiac fibrosis, maintain myocyte number, reduce myocyte size and decrease the myocardial NOX4 expression in $\mathrm{ApoE}^{-/-}$mice. A: Representative pictures of Masson staining of left ventricule. White arrows depict collagen. a (WT), b (KO), c (AST-LD), d (AST-HD). B: The results of collagen volume fraction. C: Representative picture of immunofluorescence staining of myocyte (cTnI, red). Nucleus was stained by DAPI (blue). D: The results of myocyte numbers. E: The reults of myocyte size. F: Representative pictures of the NOX4 (red, arrows) expression by immunofluorescence staining. G: The results of the percentage of NOX4-positive cells in total heart cells. H: Representative pictures of the SOD2 (red) expression by immunofluorescence
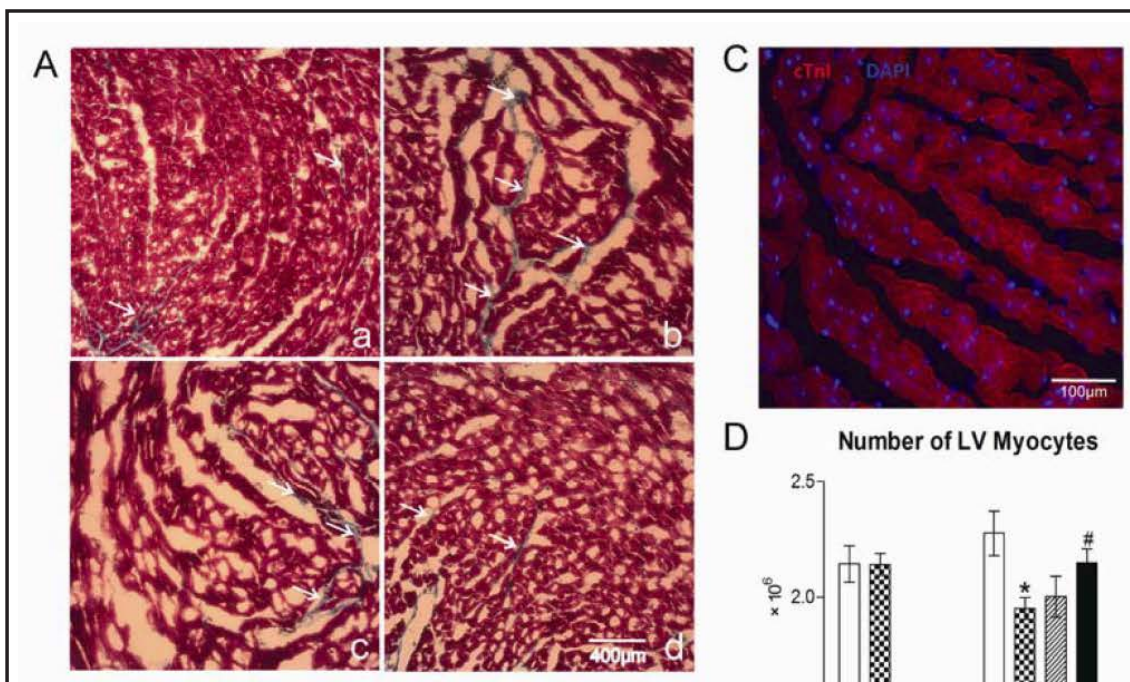

D

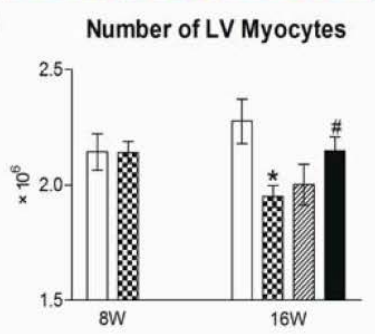

B

Collagen Volume Fraction

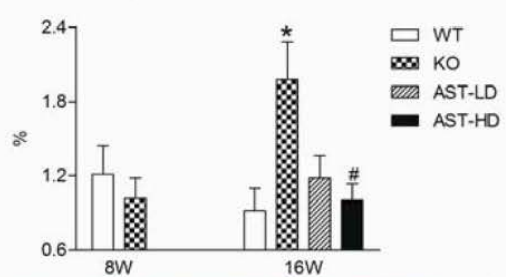

E
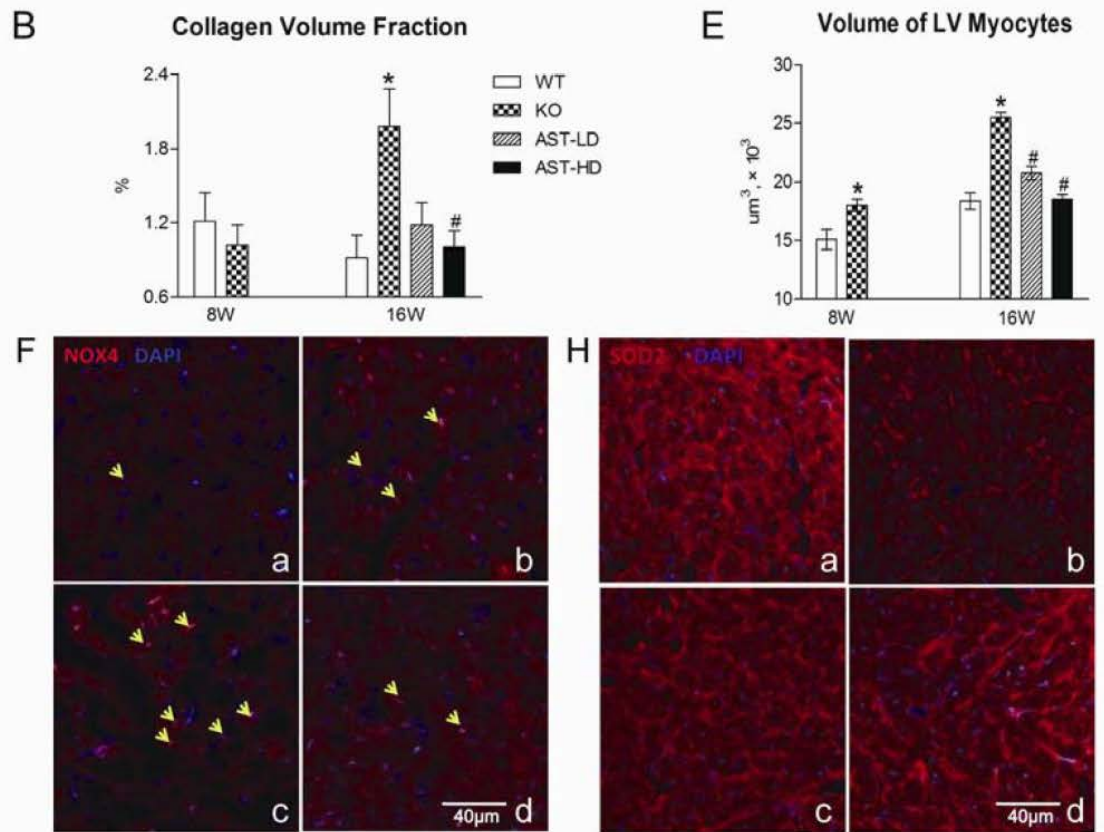

G

NOX $4^{+}$cells / Total Cells
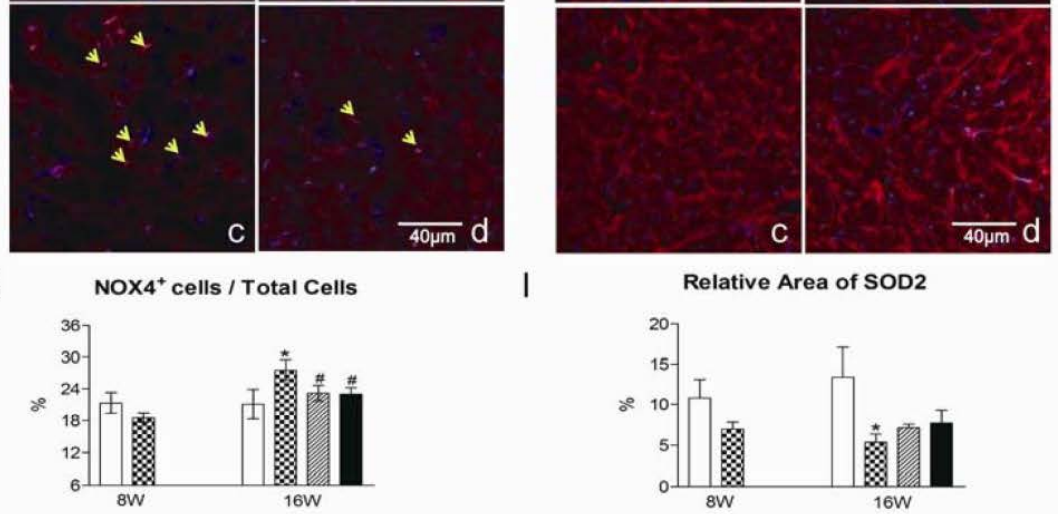

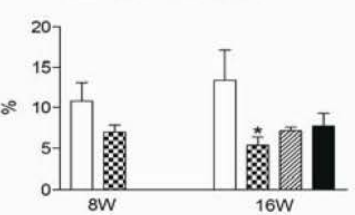

Relative Area of SOD2

staining. I: The results of the relative area of SOD2 expression. Values shown are mean \pm SD. Student's t-test was used to compare the means of two groups at 8W. ANOVA and Dunnett's test were employed in multiple comparisons at $16 \mathrm{~W} .{ }^{*}, \mathrm{P}<0.05$ vs. WT mice at 8 or 16 weeks of age ( $8 \mathrm{~W}$ or $\left.16 \mathrm{~W}\right)$; $\#, \mathrm{P}<0.05$ vs. KO animals at 16 weeks of age.

AST-IV treatment could decrease cardiac fibrosis, reduce myocyte size, and maintain myocyte number in Apo $E^{-/-}$mice

Consistent with previous reports [2, 8], hypercholesterolemia is characterized by an enhanced cardiac fibrosis. The LV collagen content showed no difference between KOs and 


\section{Cellular Physiology Cell Physiol Biochem 2017;44:2422-2438

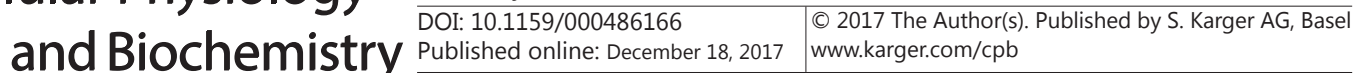 \\ Li et al.: Astragaloside IV Prevents Cardiac Remodeling in $\mathrm{ApoE}^{-/}$Mice}

WTs at 8 weeks of age. The collagen volume fraction increased over twice in KOs compared with that of WTs at 16 weeks of age, and declined nearly in half in AST-HD animals. Therefore, hypercholesterolemia was prone to developing cardiac fibrosis, and AST-IV administration inhibited fibrosis in hypercholesterolemic heart (Fig. 3A-B).

The myocardial hypertrophy in hypercholesterolemic ApoE $/$ could be induced by the changes of number and size of cardiomyocytes. The survival cardiac myocytes continue to increase in cell size in the form of hypertrophic growth. Therefore, we determined the size and number of ventricular myocytes by immunofluorescence staining with the specific cardiomyocyte marker cTnI. A 19\% increase in myocyte size was detected in hypercholesterolemic KOs at 8 weeks of age, whereas myocyte number was almost the same as WTs. At 16 weeks, a greater increase (38\%) in myocyte size and a 14\% decrease in myocyte number were found in hypercholesterolemic KOs compared with WTs. Myocyte size was markedly suppressed in AST-LD (19\%) and AST-HD (27\%), and the number of ventricular myocytes was greatly recovered in AST-HD mice compared with KOs (Fig. 3C-E).

AST-IV treatment could partly reverse the changes of transcriptional profile in ApoE ${ }^{-/-}$ mice

To examine the transcriptional profile changes in hearts of $\mathrm{ApoE}^{-/-}$and AST-IV treated mice, we studied series of genes linked to the cell cycle, proliferation, senescence, p53dependent apoptosis pathway and antioxidants. At 16 weeks of age, the mRNA expressions of CDKN1A, CDKN1B, especially CDKN2A, significantly increased in hearts of KOs with hypercholesterolemia. The expressions of CDK4, Cyclin B1, Ki67 and MCM5 were higher in KOs at 16 weeks. Transcriptions for CDKN1A, CDKN1B, CDKN2A, MCM5, Cyclin B1, D1, E1, A2 and CDK4 were decreased in KOs exposed to the low and/or high doses of AST-IV (Fig. $4 \mathrm{~A})$.

In the same way, a series of genes involved in p53-dependent apoptosis pathway, including p53, TP53, Bax, Bcl2, Mcl1, caspase-3, Mdm2, ATM and GADD45A, were studied. Most of the above-mentioned genes transcription was not affected in KOs at 8 weeks of age, except 1.6-fold up-regulation of p53 and 27\% down-regulation of Mcl1. However, almost all of genes in p53-dependent apoptosis pathway, excluding Bax and GADD45A, were enhanced more than 2.5 times at transcriptional level in KOs at 16 weeks of age. The transcriptional profiles of these genes were similar in AST-LD and AST-HD groups, which presented marked decreasing mRNA expressions of genes related to p53-dependent apoptosis pathway (Fig. 4B).

No alteration in gene expressions associated with oxidative stress and antioxidant defense, including Duox1, Srxn1, NOX1, NOX4, GPX2, SOD1, SOD2, was detected at 8 weeks of age. At 16 weeks, most of these genes, except Duox1 and SOD1, were up-regulated at transcriptional level in KOs compared with WTs. However, the mRNA expressions of these genes were decreased in both AST-IV treated groups (Fig. 4C).

AST-IV treatment could increase the number of Ki67 positive myocytes, and reduce $p 16^{\text {INK4a }}$ positive myocytes in ApoE $E^{-/}$mice

The abnormities of myocyte size and number, and the alterations of related gene expression implied the disturbed states of proliferation, apoptosis and senescence in hypercholesterolemic heart. Thus, we measured the expression of the proliferative related protein Ki67 and the senescent associated protein P16 ${ }^{\text {INK4a }}$ by immunofluorescence staining in heart tissue. Cardiac troponin I (cTnI) was co-stained to identify the myocytes. On one hand, the percentage of ki67-positive myocytes of total myocytes in KOs was close to WTs at 8 weeks of age. But it was fewer than nearly four-fifths compared with WTs at 16 weeks, and was increased markedly more than three times after high dose treatment with AST-IV (Fig. 5AB). Meanwhile, the percentage of ki67-positive cells in total heart cells within counted vision fields was calculated. The result presented similar variation trend to the percentage of ki67positive myocytes in our experiments (Data not shown).The decreased protein expression 
Fig. 4. AST-IV treatment could partly reverse the changes of transcriptional profile in ApoE ${ }^{-/-}$mice. A-C: Transcriptional expression is expressed as fold changes compared to control (WTs) at 16W. Values shown are mean \pm SD. ANOVA and Dunnett's test were employed in multiple comparisons at $16 \mathrm{~W} .{ }^{*}, \mathrm{P}<0.05 \mathrm{vs}$. WT mice at 16 weeks of age (16W); \#, $\mathrm{P}<0.05$ vs. KO animals at 16 weeks of age.

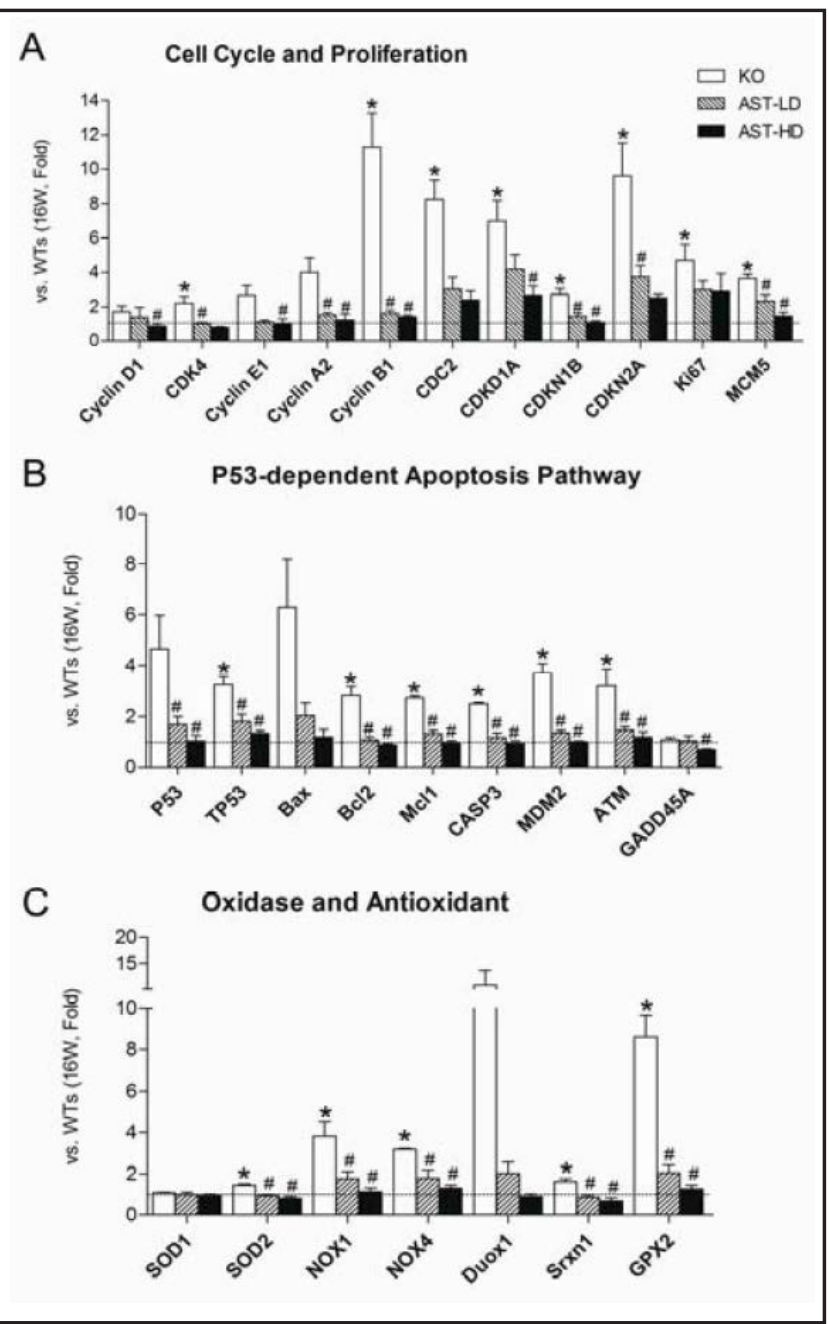

of ki67 was not consistent with the result of its increased mRNA expression (Fig. 4A). On the other hand, the percentage of $\mathrm{p} 16^{\text {INK4a }}$-positive myocytes in hypercholesterolemic KOs did not differ from WTs at 8 weeks. However, this rate in KOs exceeded 2.9-fold to WTs at 16 weeks. Decreases in the percentage of $16^{\text {INK4a }}$-positive myocytes were noted in AST-LD (39\%) and AST-HD (60\%) groups, compared with KOs at 16 weeks (Fig. 5C-D). Correspondingly, similar changes in the percentage of p16 ${ }^{\text {INK4a }}$-positive cells in total heart cells occurred in the KOs and AST treated mice (Data not shown), which was consistent with its above-mentioned altered gene expression of CDKN2A.

AST-IV treatment could inhibit cell apoptosis in ApoE ${ }^{-/-}$mice

To determine the impacts of hypercholesterolemia on cardiomyocyte homeostasis, apoptotic cell death was examined further. In KOs group at 8 weeks of age, few myocyte apoptosis was occurred $(<2 \%)$, and it was not differ from WTs. Apoptotic myocytes were detected extensively in KOs, and the percentage of apoptotic myocytes in total myocytes was almost 23-fold higher than that of WTs at 16 weeks. After intervention of AST-IV for 8 weeks, the extent of apoptotic cell death was suppressed in AST-LD (87\%) and AST-HD (90\%) groups (Fig. 5E-F). The percentage of apoptotic cells in total cardiac cells displayed similar changes (Fig. 5G). These data were consistent with the changes of the above-mentioned mRNA expression of p53-dependent apoptosis pathway. Thus, hypercholesterolemia triggered apoptosis in heart, and AST-IV treatment obviously attenuated the apoptotic challenge. 
Fig. 5. AST-IV treatment could increase myocyte proliferation, decrease myocyte senescence and apoptosis in $\mathrm{ApoE}^{-/-}$mice. A: Representative pictures of the proliferative related protein Ki67 (dark pink in nucleus) and cTnI (green) by double-immunofluorescence staining in groups a (WT), b (KO), c (AST-LD), and $d$ (AST-HD). $B$ : The results of the percentage of ki67-positive myocytes in total myocytes. C: Representative pictures of the senescent associated P16 ${ }^{\mathrm{INK} 4 \mathrm{a}}$ (pink in nucleus) and cTnI (green) by double-immunofluorescence staining. D: The results of the percentage of P16 ${ }^{\text {INK4a }}$-positive myocytes in total myocytes. E: Repre-

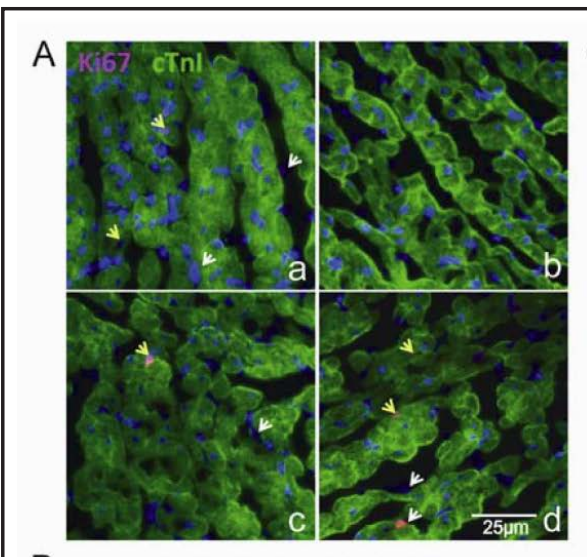

B
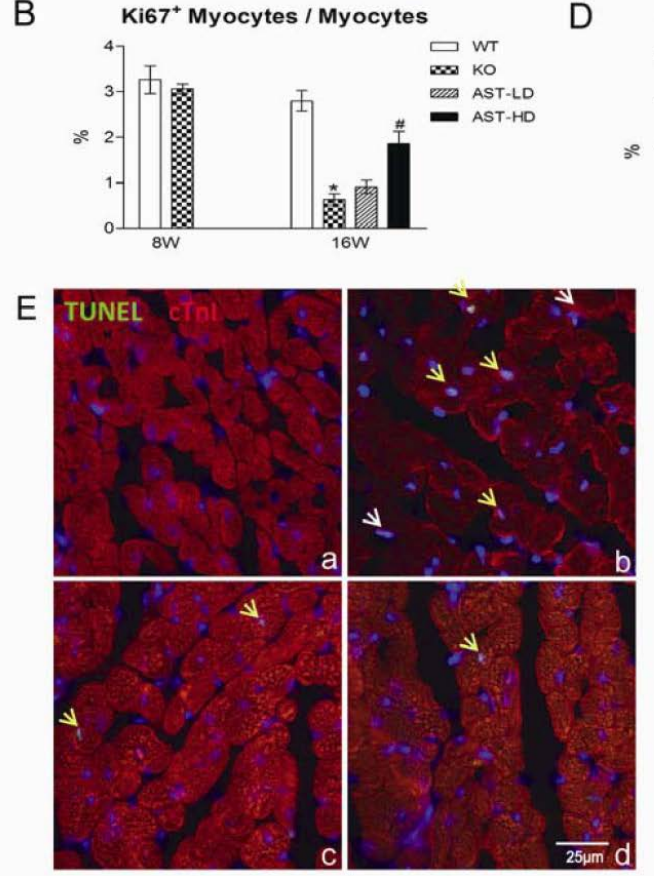

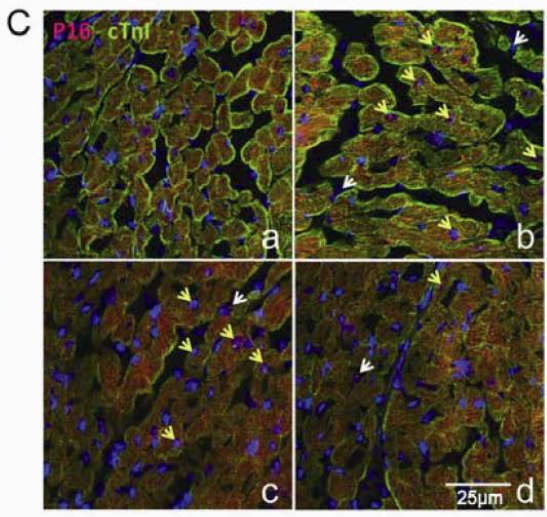

$\mathrm{D}$

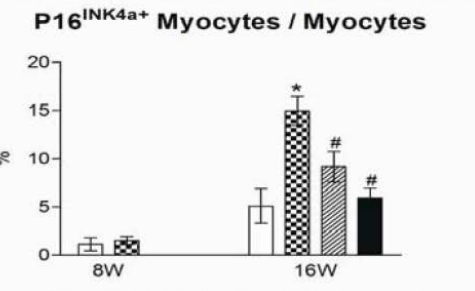

F Apoptosis ${ }^{+}$Myocytes / Myocvtes



G Apoptosis* cells/ Total cells

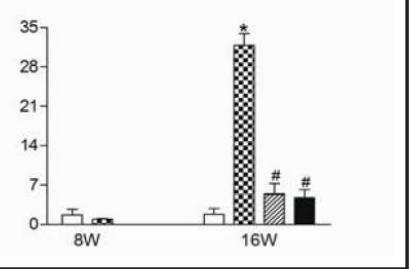

sentative pictures of the apoptotic cells (green in nucleus) and cTnI (red) by TUNEL assay with immunofluorescence staining. F: The result of the percentage of apoptotic myocytes in total myocytes . G: The result of the percentage of apoptotic cells in total cardiac cells. Nucleus was stained by DAPI. Yellow arrows depict myocytes expressing Ki67/P16 ${ }^{\mathrm{INK} 4 \mathrm{a}}$ or apoptotic myocytes, and white arrows lable non-cardiac myocytes expressing Ki67/P16 ${ }^{\text {INK4a }}$ or apoptotic non-cardiac myocytes. Values shown are mean \pm SD. Student's t-test was used to compare the means of two groups at 8W. ANOVA and Dunnett's test were employed in multiple comparisons at $16 \mathrm{~W}$. ${ }^{*}, \mathrm{P}<0.05$ vs. WT mice at 8 or 16 weeks of age ( $8 \mathrm{~W}$ or $\left.16 \mathrm{~W}\right)$; $\#, \mathrm{P}<0.05$ vs. K0 animals at 16 weeks.

\section{AST-IV treatment could decrease NOX4 expression in ApoE-1- mice}

Hypercholesterolemia is generally associated with oxidative stress and antioxidant defense. NADPH oxidase 4 (NOX4) related to superoxide metabolism, and SOD involved in reactive oxygen species (ROS) metabolism were determined by immunofluorescence staining in this study. As shown in Fig. 3F-I, there were no differences in the percentage of NOX4positive cells in total heart cells and the positive expression areas of SOD1/2 between KOs and WTs at 8 weeks of age. Nevertheless, at 16 weeks, the percentage of NOX4-positive cells in total heart cells in KOs was higher than WTs, and the positive expression areas of SOD2 in KOs were significantly smaller than that in WTs. No difference was existed in the relative 


\section{Cellular Physiology Cell Physiol Biochem 2017;44:2422-2438

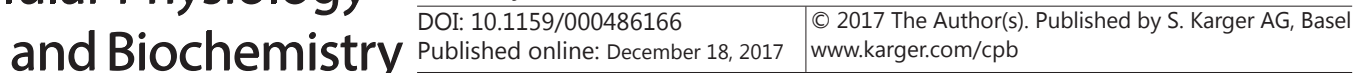

Li et al.: Astragaloside IV Prevents Cardiac Remodeling in $\mathrm{ApoE}^{-/-}$Mice

expression of SOD1 between KOs and WTs (Data not shown). After the treatment of AST-IV, the percentage of NOX4-positive cells was significantly decreased in the hearts of AST-LD and AST-HD groups. However, the expressions of SOD1 and SOD2 were not altered in the hearts of AST-LD and AST-HD groups. The results of protein expressions of NOX4, SOD1 and SOD2 were consistent with the relevant mRNA expressions at 8 and 16 weeks, respectively.

\section{Discussion}

Hypercholesterolemia is one of contributors to cardiac hypertrophy that occurs in humans. ApoE-deficient mice develop marked hypercholesterolemia and spontaneous atherosclerosis on a normal chow diet, and thus were produced as an animal model for hypercholesterolemia. ApoE, a 34-kD glycoprotein, is a major component of plasma lipoproteins that serves as a ligand for receptor mediated clearance of several classes of lipoproteins from plasma, including chylomicrons, very low density lipoprotein (VLDL), and lipoprotein remnants. ApoE is fundamentally involved in the lipid and cholesterol homeostasis. An increasing number of studies have demonstrated the association between the ApoE genotype and oxidative stress, immunomodulatory/anti-inflammatory properties, mitochondrial and endoplasmic reticulum (ER) stress-related processes [41, 42]. ApoE is highly expressed in the mouse heart, whereas its expression is low in skeletal muscles [43]. The cardiac phenotype in ApoE-deficient mice may be in part due to an impact of loss of the multifunctional nature of the ApoE protein. AST-IV is a kind of pentacyclic triterpenoid. There were few studies focused on the effects of AST-IV on blood lipids. In the present study, we observed AST-IV (1 mg/kg and $10 \mathrm{mg} / \mathrm{kg}$ by introperitoneally injection) treatment for 8 weeks could not decrease the concentrations of plasma TC, and LDL-C levels in ApoE ${ }^{-/-}$mice fed standard diet. This result is not consistent with that of Qin et al [44], which reported that AST-IV ( $40 \mathrm{mg} / \mathrm{kg}$ by oral gavage) for 12 weeks could down-regulate plasma TG, TC, and LDL-C levels and up-regulate HDL-C level in $\mathrm{ApoE}^{-/-}$mice fed high-fat Western diet. In fructose-fed rats, AST-IV ( $0.5 \mathrm{mg} / \mathrm{kg}$ and $2 \mathrm{mg} / \mathrm{kg}$ by introperitoneally injection) treatment for 8 weeks could reduce triglyceride levels [45]. The different doses, methods of administration and duration of AST-IV treatment might be responsible for these inconsistent results. The effects of AST-IV on plasma lipids need to be further confirmed and compared with the present lipid-lowering drugs in clinic, such as 3-hydroxy-3-methylglutaryl-coenzyme A (HMG-CoA) inhibitor statins.

Hyperlipidemia may be an early initiator of cardiac remodeling. $\mathrm{ApoE}^{-/-}$mice are more susceptible to cardiac hypertrophy and dysfunction [10,30]. Compared with agematched wild-type mice, ApoE $\mathrm{E}^{-/-}$mice had an increased total ventricular weight, left ventricular weight and HW/BW ratio, a larger LV end diastolic dimension and a smaller LVEF $[10,11,30]$. But several other studies $[46,47]$ failed to observe cardiac hypertrophy in $\mathrm{ApoE}^{-/-}$mice. In this study, the $\mathrm{ApoE}^{-/-}$mice with hypercholesterolemia presented cardiac remodeling, characterized by increased cardiac weights, dilated chamber and impaired ventricular function, interstitial fibrosis, and increased myocyte size and decreased myocyte number. The aortic stiffness and arterial hypertension in hypercholesterolemia may lead to increased cardiac afterload, thus contribute to cardiac hypertrophy in $\mathrm{ApoE}^{-/-}$mice [48]. Previous studies have identified some common molecular signal transduction pathways and the regulators of pathological cardiac hypertrophic response, which include calcineurin, NFAT, natriuretic peptides, IL-6 cytokine family, Gq/G11 signaling, PI3K, MAPK pathways, RAS, polypeptide growth factors, nitric oxide (NO), TNF- $\alpha$, peroxisome proliferator activated receptor (PPAR) and JAK/STAT pathway [49]. It has been proved that pathological cardiac hypertrophy can be prevented or reversed by modulating these signaling pathways. In addition to the primary lipid-lowering effect, the statins are speculated to have additional effects on reducing cardiac hypertrophy by inactivating PPAR pathway and attenuating free radical formation $[2,50]$. Moreover, blockade of angiotensin signaling via angiotensinconverting enzyme inhibitor or receptor antagonism efficiently restored normal myocardial 
function and cardiac structure during hypercholesterolemia independent of blood pressure change [51, 52]. In this study, the ApoE ${ }^{-/-}$mice treated with AST-IV presented decrease of ventricular weight, interstitial fibrosis and myocyte size, and preservation of the myocyte number and cardiac systolic function, which implied that AST-IV could prevent cardiac remodeling in $\mathrm{ApoE}^{-/-}$mice with hypercholesterolemia even without lowering blood lipids levels. We postulated that certain common signal transduction pathways and regulators were the targets of AST-IV for its beneficial effects on hypercholesterolemia. Previous studies have confirmed that AST-IV could reverse or delay cardiac remodeling caused by various reasons, such as viral infection [35], isoproterenol (ISO) [26, 31, 53] and lipopolysaccharide (LPS) [27]. AST-IV protected against ISO-induced cardiac hypertrophy via inhibiting p65 translocation and increasing PPAR $\gamma$ coactivator $1 \alpha$ (PGC-1 $\alpha$ ) [28]. TLR4/NF-small ka and Cyrillic B signaling pathways were the other targets for the effects of AST-IV against ISOinduced cardiac hypertrophy [26]. AST-IV prevented myocardial fibrosis in coxsackievirus B3-induced dilated cardiomyopathy via down-regulating TGF- $\beta 1$, Smad 4 and $p$-Smad2/3 expressions [35]. AST-IV attenuated LPS-induced cardiac hypertrophy through inhibiting the activation of $\mathrm{Ca}^{2+}$ /calcineurin, GATA-4, and the nuclear translocation of NFAT-3 [27]. AST-IV strongly blocked Rheb/mTORC1 signaling pathway and reduced its downstream phosphoS6K levels in myocardial infarction (MI) and transverse aortic constriction (TAC) mice model [30]. AST-IV has shown the ability to attenuate oxidative stress and suppress the activation of the mitochondrial apoptosis via PI3K/Akt signaling pathway [32]. More and more studies showed that AST-IV exerted its cardioprotective function through a number of signaling pathways and multiple target molecules. In this study, we mainly observe the effects of AST-IV on cardiac homeostasis in hypercholesterolemic heart, including the cellular fates of proliferation, senescence and apoptosis. The state of oxidative stress was simultaneously investigated.

The adult myocardium has limited capacity to preserve, renew or rejuvenate itself. The survival, proliferation, and senescence of cardiac cells at rest and following the exposure to different stressors are affected by the changes of local micro-environment. The alterations may act at transcriptional and post-transcriptional levels, and be effectively modulated by natural or synthetic active compounds. In this study, decreased cell proliferation and accelerated senescence in the heart of $\mathrm{ApoE}^{-/-}$mice were noted, which were consistent with the previous research [21]. The coexistence of decreased total number of cardiomyocytes and decreased proliferation marker expression implied that the micro-environmental change induced by hypercholesterolemia weakened the intact proliferative activity of cardiomyocytes. The intervention of AST-IV effectively increased the percentages of ki67positive myocytes and ki67-positive cells in the heart of hypercholesterolemic mice. The total number of cardiomyocytes was maintained by AST-IV treatment. The results suggested that AST-IV functioned as a cardiac regenerator.

The transcriptional levels of genes related to cell cycle were analyzed in this study. CDKs are serine-threonine kinases, which become active upon formation of a complex with the corresponding cyclin. Cell cycle progression requires accurate CDK-cyclin complexes formation at the corresponding checkpoints. The CDK4-Cyclin D complex plays the most crucial role at the G1/S-phase transition. Further the main active complex at the G2/M transition is cdc2-Cyclin E. CDKIs are negative regulators of CDKs. The expressions of cyclins and the corresponding CDKs are significantly down-regulated in hearts afterbirth, accompanied by up-regulated expression of CDKIs. Whether alteration of these regulators causes the decrease in myocyte proliferation afterbirth or vice versa remains a mystery. We demonstrated that the mild change of expressions of CDKs and cyclins in this study, except cyclin B1 and cdc2. However, the expression of CDKIs, including p21, p27 and p16, obviously increased in hypercholesterolemic hearts, functioned dominantly, and involved in cell cycle arrest. The treatment of AST-IV significantly down-regulated the expression of CDKIs, and thus might promote the myocyte proliferation.

Cellular senescence is an anti-proliferative process of protecting irreversible cell cycle arrest in certain pathologic conditions induced by genetic and/or epigenetic abnormalities. 
The senescent cells cease to cycle progression, consequently lead to inability of maintenance of tissue homeostasis. p16 belongs to INK4 family of CDKIs, and selectively blocks CDK4/6Cyclin D complex formation and subsequent enzymatic activity. The expression of p16 has been suggested to be low in young adult hearts and increase in aged hearts. Thus, p16 is regarded as one of markers of cellular aging or senescence. Tumor suppressor p53 can facilitate cell cycle arrest and senescence program in cells in response to stress [54]. The high expressions of p16 and p53 hamper the resuming cell cycle progression for a senescent cell [55]. Myocyte senescence is associated with oxidative stress, chronic adrenergic signaling, renin-angiotensin-aldosterone signaling (RAAS) and mTORC pathway [55]. The mitochondrial functional impairment induces oxidative stress, serves as a primary inciting stimulus for transition into senescence. The cardiomyocytes with hyper-activation of the RAAS developed an aged phenotype. Over-stimulation of mTORC1 pathway through growth factors promoted cardiac senescence. Previous studies proved that AST-IV could resist the cardiac adrenergic [28] and angiotensin stimulation [56], inhibit mTORC1 [30], and thus protect against cardiac remodeling. In this study, we found that the hypercholesterolemic heart presented high expressions of p16 and p53, which could be reversed after AST-IV treatment. It suggested that AST-IV could impede the process of cardiac senescence.

Enhanced apoptosis is another reason for the decreased total number of cardiomyocytes in pathologic conditions. Apoptosis is a programmed cell death mechanism which is essential for the maintenance of tissue homeostasis. One of the major apoptosis signaling pathways involves the p53 tumor suppressor. Cellular p53 levels are low or undetectable under normal conditions by continuous ubiquitylation (e.g. MDM2) and subsequent degradation, and increased by post-translational modifications (e.g. phosphorylated by ATM) under stress signals stimulation. As a nuclear transcription factor, activated p53 enhanced expression of a number of downstream genes containing p53-binding sites within their regulatory regions [57]. p53 induces cell apoptosis by activating mitochondrial- and death receptor-mediated caspase-dependent apoptotic pathways. The mitochondrial pathway is mainly dominated by p53 effector Bcl-2 family of protein (e.g. Bax/Bcl-2). We found that the expressions of gene associated with p53-apoptosis pathway, including TP53, Bax, Bcl2, Mcl1, caspase 3, MDM2, and ATM, were changed in heart of $\mathrm{ApoE}^{-/-}$mice. These results were consistent with the recent study [58], which demonstrated that the higher expressions of p53 and caspase-3/9 in heart of ApoE $\mathrm{E}^{-/-}$mice. We also demonstrated that the percentages of apoptotic myocytes and apoptotic cells in the heart of ApoE ${ }^{-/}$mice were significantly higher than those of wild-type mice at 16 weeks, and were suppressed after the treatment of AST-IV. The transcriptional changes of p53-apoptotic pathway in hypercholesterolemia were also reversed after AST-IV treatment. Previous studies reported that AST-IV exerted anti-apoptosis effect on cardiomyocyte by attenuating oxidative stress and calpain-1 activation [31], inhibiting the activation of mitochondrial apoptotic pathway via PI3K/Akt pathway [32]. Whether p53dependent apoptosis pathway is another target pathway for the anti-apoptosis effect of ASTIV needs to be further investigated.

There is a fine-tuned balance between oxidant and anti-oxidant molecules in cells. Enzymatic sources for ROS formation include the mitochondrial respiratory chain, NADPH oxidases (NOX), and so on. The antioxidant systems include enzymes (e.g. SOD, catalase) and endogenous non-enzymatic antioxidant molecules (e.g. NO). Therefore, the excess formation of ROS by oxidant systems and/or insufficient removal capacity of anti-oxidant systems results in oxidative stress. The increased ROS production in the hypercholesterolemic heart was mainly caused by increased NOX activity, especially NOX4, which can be related to transcriptional, posttranscriptional, or epigenetic regulation of NOX4 expression [16]. Decreased cardiac expression and activity of antioxidants, such as SOD, is another possible explanation for increased ROS in hypercholesterolemic hearts. The precise molecular mechanism by which hypercholesterolemia up-regulates myocardial oxidant enzymes and down-regulates antioxidant enzymes remain to be elucidated. It was reported that excess production of ROS in $\mathrm{ApoE}^{-/-}$mice triggered several signalings such as lipid oxidation, DNA damage, senescence and production of pro-inflammatory substances 


\section{Cellular Physiology Cell Physiol Biochem 2017;44:2422-2438 \begin{tabular}{l|l|l} 
and Biochemistry Published online: December 18, 2017 & $\begin{array}{l}\text { (c) } 2017 \text { The Author(s). Published by S. Karger AG, Basel } \\
\text { www.karger.com/cpb }\end{array}$ \\
\hline
\end{tabular}

[48]. Accumulating studies suggested that elevated oxidative stress played an important role in hypercholesterolemia-induced cardiac complications. Therefore, modulation of hypercholesterolemia-induced myocardial oxidative stress is a rational approach to prevent or treat cardiac consequences. In this study, we confirmed that the expression of NOX4 increased and SOD2 decreased in the hearts of ApoE-/- mice, which could be reversed after the treatment of AST-IV. AST-IV alleviated oxidative stress in many pathological conditions [59] by inhibiting oxidants (e.g. NOXs) and/or strengthening antioxidants (e.g. SOD).

\section{Conclusions}

In summary, our results indicated that $\mathrm{ApoE}^{-/-}$mice with hypercholesterolemia presented cardiac remodeling, characterized by increased cardiac weights, dilated chamber and impaired ventricular function, cardiac fibrosis, increased myocyte size and decreased myocyte number. Meanwhile, the cardiac homeostasis, including cell proliferation, senescence and apoptosis, and oxidative stress were changed in hypercholesterolemic heart. Neither 1 $\mathrm{mg} / \mathrm{kg}$ nor $10 \mathrm{mg} / \mathrm{kg}$ AST-IV treatment lasting for 8 weeks could reduce the plasma lipids levels of ApoE $/$ - mice. But the mice with high dose AST-IV treatment presented better effects on preventing cardiac remodeling, maintaining cardiac homeostasis, inhibiting senescence and apoptosis, and reducing oxidative stress.

\section{Acknowledgment}

This work was supported by the National Natural Science Foundation of China (Nos. 81170220, and 81100156), Natural Science Foundation of Jiangsu province (No. BK20151587), and Priority Academic Program Development of Jiangsu Higher Education Institutions. We thank Yiming Wang M.A. (The State Key Laboratory of Reproductive Medicine, Department of Anatomy, Histology and Embryology, Nanjing Medical University, Nanjing, China), for his generously providing us with $\mathrm{p} 16^{\mathrm{INK} 4 \mathrm{a}}$ antibody.

\section{Disclosures}

On behalf of all other authors, the corresponding author states that there is no conflict of interest.

\section{References}

1 Ulasova E, Perez J, Hill BG, Bradley WE, Garber DW, Landar A, Barnes S, Prasain J, Parks DA, Dell'Italia LJ, Darley-Usmar VM: Quercetin prevents left ventricular hypertrophy in the Apo E knockout mouse. Redox Biol 2013;1:381-386.

2 Qin YW, Ye P, He JQ, Sheng L, Wang LY, Du J: Simvastatin inhibited cardiac hypertrophy and fibrosis in apolipoprotein E-deficient mice fed a "Western-style diet" by increasing PPAR alpha and gamma expression and reducing TC, MMP-9, and Cat S levels. Acta Pharmacol Sin 2010;31:1350-1358.

-3 Barter P, Gotto AM, LaRosa JC, Maroni J, Szarek M, Grundy SM, Kastelein JJ, Bittner V, Fruchart JC, Treating to New Targets I: HDL cholesterol, very low levels of LDL cholesterol, and cardiovascular events. N Engl J Med 2007;357:1301-1310.

4 Chyou PH, Eaker ED: Serum cholesterol concentrations and all-cause mortality in older people. Age Ageing 2000;29:69-74.

5 Goldbourt U, Holtzman E, Neufeld HN: Total and high density lipoprotein cholesterol in the serum and risk of mortality: evidence of a threshold effect. Br Med J (Clin Res Ed) 1985;290:1239-1243. 


\section{Cellular Physiology Cell Physiol Biochem 2017;44:2422-2438 \begin{tabular}{ll|l} 
and Biochemistry & Published online: December 18, 2017 & $\begin{array}{l}\text { (c) } 2017 \text { The Author(s). Published by S. Karger AG, Basel } \\
\text { www.karger.com/cpb }\end{array}$
\end{tabular}}

6 Sundstrom J, Lind L, Vessby B, Andren B, Aro A, Lithell H: Dyslipidemia and an unfavorable fatty acid profile predict left ventricular hypertrophy 20 years later. Circulation 2001;103:836-841.

-7 Celentano A, Crivaro M, Roman MJ, Pietropaolo I, Greco R, Pauciullo P, Lirato C, Devereux RB, de Simone G: Left ventricular geometry and arterial function in hypercholesterolemia. Nutr Metab Cardiovasc Dis 2001;11:312-319.

-8 Nakashima Y, Plump AS, Raines EW, Breslow JL, Ross R: ApoE-deficient mice develop lesions of all phases of atherosclerosis throughout the arterial tree. Arterioscler Thromb 1994;14:133-140.

-9 Wu JH, Hagaman J, Kim S, Reddick RL, Maeda N: Aortic constriction exacerbates atherosclerosis and induces cardiac dysfunction in mice lacking apolipoprotein E. Arterioscler Thromb Vasc Biol 2002;22:469475.

10 Yang R, Powell-Braxton L, Ogaoawara AK, Dybdal N, Bunting S, Ohneda O, Jin H: Hypertension and endothelial dysfunction in apolipoprotein E knockout mice. Arterioscler Thromb Vasc Biol 1999;19:27622768.

11 Wang YX: Cardiovascular functional phenotypes and pharmacological responses in apolipoprotein E deficient mice. Neurobiol Aging 2005;26:309-316.

12 Hartley CJ, Reddy AK, Madala S, Martin-McNulty B, Vergona R, Sullivan ME, Halks-Miller M, Taffet GE, Michael LH, Entman ML, Wang YX: Hemodynamic changes in apolipoprotein E-knockout mice. Am J Physiol Heart Circ Physiol 2000;279:H2326-2334.

13 Shimabukuro M, Okawa C, Yamada H, Yanagi S, Uematsu E, Sugasawa N, Kurobe H, Hirata Y, Kim-Kaneyama JR, Lei XF, Takao S, Tanaka Y, Fukuda D, Yagi S, Soeki T, Kitagawa T, Masuzaki H, Sato M, Sata M: The pathophysiological role of oxidized cholesterols in epicardial fat accumulation and cardiac dysfunction: a study in swine fed a high caloric diet with an inhibitor of intestinal cholesterol absorption, ezetimibe. J Nutr Biochem 2016;35:66-73.

-14 Huang Y: Cardiac Systolic and Diastolic Dysfunction After a Cholesterol-Rich Diet. Circulation 2003;109:97102.

15 Lee H, Yoo YS, Lee D, Song EJ: Cholesterol induces cardiac hypertrophy by activating the AKT pathway. J Steroid Biochem Mol Biol 2013;138:307-313.

16 Csonka C, Sárközy M, Pipicz M, Dux L, Csont T: Modulation of Hypercholesterolemia-Induced Oxidative/ Nitrative Stress in the Heart. Oxid Med Cell Longev 2016;2016:1-23.

17 Rota M, LeCapitaine N, Hosoda T, Boni A, De Angelis A, Padin-Iruegas ME, Esposito G, Vitale S, Urbanek K, Casarsa C, Giorgio M, Luscher TF, Pelicci PG, Anversa P, Leri A, Kajstura J: Diabetes promotes cardiac stem cell aging and heart failure, which are prevented by deletion of the p66shc gene. Circ Res 2006;99:42-52.

18 Mollova M, Bersell K, Walsh S, Savla J, Das LT, Park SY, Silberstein LE, Dos Remedios CG, Graham D, Colan S, Kuhn B: Cardiomyocyte proliferation contributes to heart growth in young humans. Proc Natl Acad Sci U S A 2013;110:1446-1451.

19 Tao Z, Chen B, Tan X, Zhao Y, Wang L, Zhu T, Cao K, Yang Z, Kan YW, Su H: Coexpression of VEGF and angiopoietin-1 promotes angiogenesis and cardiomyocyte proliferation reduces apoptosis in porcine myocardial infarction (MI) heart. Proc Natl Acad Sci U S A 2011;108:2064-2069.

20 Nepomniashchikh LM, Lushnikova EL, Larionov PM, Shurygin MG: [Myocardial regeneration: proliferative potential of cardiomyocytes and induction of cardiomyogenesis in alterative and plastic cardiac failure]. Vestn Ross Akad Med Nauk 2010;3-11.

-21 Lushnikova EL, Nepomnyashchikh LM, Klinnikova MG, Molodykh OP, Yuzhik EI, Nepomnyashchikh RD, Pichigin VI: Proliferative activity of cadriomyocytes in chronic hypercholesterolemia. Bull Exp Biol Med 2014;156:578-583.

22 He CS, Liu YC, Xu ZP, Dai PC, Chen XW, Jin DH: Astragaloside IV Enhances Cisplatin Chemosensitivity in Non-Small Cell Lung Cancer Cells Through Inhibition of B7-H3. Cell Physiol Biochem 2016;40:1221-1229.

23 Zhang L, Li Z, He W, Xu L, Wang J, Shi J, Sheng M: Effects of Astragaloside IV Against the TGF-beta1-Induced Epithelial-to-Mesenchymal Transition in Peritoneal Mesothelial Cells by Promoting Smad 7 Expression. Cell Physiol Biochem 2015;37:43-54.

-24 Liu ZL, Liu ZJ, Liu JP, Kwong JS: Herbal medicines for viral myocarditis. Cochrane Database Syst Rev 2012;11:CD003711.

25 Wang H, Zhang Y, Xia T, Wei W, Chen F, Guo X, Li X: Synergistic promotion of blood vessel regeneration by astragaloside IV and ferulic acid from electrospun fibrous mats. Mol Pharm 2013;10:2394-2403. 


\section{Cellular Physiology Cell Physiol Biochem 2017;44:2422-2438 \begin{tabular}{l|l} 
and Biochemistry Published online: December 18, 2017 & $\begin{array}{l}\text { (c) } 2017 \text { The Author(s). Published by S. Karger AG, Basel } \\
\text { www.karger.com/cpb }\end{array}$
\end{tabular}}

26 Yang J, Wang HX, Zhang YJ, Yang YH, Lu ML, Zhang J, Li ST, Zhang SP, Li G: Astragaloside IV attenuates inflammatory cytokines by inhibiting TLR4/NF-small ka, CyrillicB signaling pathway in isoproterenolinduced myocardial hypertrophy. J Ethnopharmacol 2013;150:1062-1070.

27 Lu M, Wang H, Wang J, Zhang J, Yang J, Liang L, Maslov LN: Astragaloside IV protects against cardiac hypertrophy via inhibiting the Ca2+/CaN signaling pathway. Planta Med 2014;80:63-69.

28 Zhang S, Tang F, Yang Y, Lu M, Luan A, Zhang J, Yang J, Wang H: Astragaloside IV protects against isoproterenol-induced cardiac hypertrophy by regulating NF-kappaB/PGC-1alpha signaling mediated energy biosynthesis. PLoS One 2015;10:e0118759.

-29 Zhao Z, Wang W, Wang F, Zhao K, Han Y, Xu W, Tang L: Effects of Astragaloside IV on heart failure in rats. Chin Med 2009;4:6.

-30 Wu X, Cao Y, Nie J, Liu H, Lu S, Hu X, Zhu J, Zhao X, Chen J, Chen X, Yang Z, Li X: Genetic and pharmacological inhibition of Rheb1-mTORC1 signaling exerts cardioprotection against adverse cardiac remodeling in mice. Am J Pathol 2013;182:2005-2014.

-31 Mei M, Tang F, Lu M, He X, Wang H, Hou X, Hu J, Xu C, Han R: Astragaloside IV attenuates apoptosis of hypertrophic cardiomyocyte through inhibiting oxidative stress and calpain-1 activation. Environ Toxicol Pharmacol 2015;40:764-773.

32 Jia Y, Zuo D, Li Z, Liu H, Dai Z, Cai J, Pang L, Wu Y: Astragaloside IV inhibits doxorubicin-induced cardiomyocyte apoptosis mediated by mitochondrial apoptotic pathway via activating the PI3K/Akt pathway. Chem Pharm Bull (Tokyo) 2014;62:45-53.

33 Guan FY, Yang SJ, Liu J, Yang SR: Effect of astragaloside IV against rat myocardial cell apoptosis induced by oxidative stress via mitochondrial ATP-sensitive potassium channels. Mol Med Rep 2015;12:371-376.

-34 Li L, Tao HY, Chen JB: [Anti-apoptosis effect of astragaloside on adriamycin induced rat's cardiotoxicity]. Zhongguo Zhong Xi Yi Jie He Za Zhi 2006;26:1011-1014.

- 35 Chen P, Xie Y, Shen E, Li GG, Yu Y, Zhang CB, Yang Y, Zou Y, Ge J, Chen R, Chen H: Astragaloside IV attenuates myocardial fibrosis by inhibiting TGF-beta1 signaling in coxsackievirus B3-induced cardiomyopathy. Eur J Pharmacol 2011;658:168-174.

-36 Zhang ZC, Li SJ, Yang YZ: [Effect of astragaloside on myocardial fibrosis in chronic myocarditis]. Zhongguo Zhong Xi Yi Jie He Za Zhi 2007;27:728-731.

-37 Hu JY, Han J, Chu ZG, Song HP, Zhang DX, Zhang Q Huang YS: Astragaloside IV attenuates hypoxia-induced cardiomyocyte damage in rats by upregulating superoxide dismutase-1 levels. Clin Exp Pharmacol Physiol 2009;36:351-357.

-38 De Angelis A, Piegari E, Cappetta D, Marino L, Filippelli A, Berrino L, Ferreira-Martins J, Zheng H, Hosoda T, Rota M, Urbanek K, Kajstura J, Leri A, Rossi F, Anversa P: Anthracycline cardiomyopathy is mediated by depletion of the cardiac stem cell pool and is rescued by restoration of progenitor cell function. Circulation 2010;121:276-292.

-39 Schmittgen TD, Livak KJ: Analyzing real-time PCR data by the comparative C(T) method. Nat Protoc 2008;3:1101-1108.

40 Yam CH, Fung TK, Poon RY: Cyclin A in cell cycle control and cancer. Cell Mol Life Sci 2002;59:1317-1326.

41 Jofre-Monseny L, Minihane AM, Rimbach G: Impact of apoE genotype on oxidative stress, inflammation and disease risk. Mol Nutr Food Res 2008;52:131-145.

-42 Dose J, Huebbe P, Nebel A, Rimbach G: APOE genotype and stress response - a mini review. Lipids Health Dis 2016;15:121.

43 Sullivan PM, Mezdour H, Aratani Y, Knouff C, Najib J, Reddick RL, Quarfordt SH, Maeda N: Targeted replacement of the mouse apolipoprotein E gene with the common human APOE3 allele enhances dietinduced hypercholesterolemia and atherosclerosis. J Biol Chem 1997;272:17972-17980.

44 Qin H, Liu P, Lin S: Effects of Astragaloside IV on the SDF-1/CXCR4 Expression in Atherosclerosis of apoE(/-) Mice Induced by Hyperlipaemia. Evid Based Complement Alternat Med 2015;2015:385154.

45 Zhang N, Wang XH, Mao SL, Zhao F: Astragaloside IV improves metabolic syndrome and endothelium dysfunction in fructose-fed rats. Molecules 2011;16:3896-3907.

-46 Pereira TM, Nogueira BV, Lima LC, Porto ML, Arruda JA, Vasquez EC, Meyrelles SS: Cardiac and vascular changes in elderly atherosclerotic mice: the influence of gender. Lipids Health Dis 2010;9:87.

47 Nogueira BV, Peotta VA, Meyrelles SS, Vasquez EC: Evaluation of aortic remodeling in apolipoprotein E-deficient mice and renovascular hypertensive mice. Arch Med Res 2007;38:816-821. 


\section{Cellular Physiology Cell Physiol Biochem 2017;44:2422-2438 \begin{tabular}{l|l} 
DOI: 10.1159/000486166 & $\begin{array}{l}\text { O } 2017 \text { The Author(s). Published by S. Karger AG, Basel } \\
\text { www.karger.com/cpb }\end{array}$ \\
\hline
\end{tabular} \\ Li et al.: Astragaloside IV Prevents Cardiac Remodeling in $\mathrm{ApoE}^{-/-}$Mice}

48 Vasquez EC, Peotta VA, Gava AL, Pereira TM, Meyrelles SS: Cardiac and vascular phenotypes in the apolipoprotein E-deficient mouse. J Biomed Sci 2012;19:22.

-49 Rohini A, Agrawal N, Koyani CN, Singh R: Molecular targets and regulators of cardiac hypertrophy. Pharmacol Res 2010;61:269-280.

-50 Lee TM, Chou TF, Tsai CH: Association of pravastatin and left ventricular mass in hypercholesterolemic patients: role of 8-iso-prostaglandin f2alpha formation. J Cardiovasc Pharmacol 2002;40:868-874.

-51 Schwemmer M, Sommer 0, Bassenge E: Blockade of angiotensin signaling improves myocardial function in hypercholesterolemia independent of changes in eicosanoid release. Cardiovasc Drugs Ther 2000;14:317327.

52 Kang BY, Wang W, Palade P, Sharma SG, Mehta JL: Cardiac hypertrophy during hypercholesterolemia and its amelioration with rosuvastatin and amlodipine. J Cardiovasc Pharmacol 2009;54:327-334.

53 Lv L, Wu SY, Wang GF, Zhang JJ, Pang JX, Liu ZQ, Xu W, Wu SG, Rao JJ: Effect of astragaloside IV on hepatic glucose-regulating enzymes in diabetic mice induced by a high-fat diet and streptozotocin. Phytother Res 2010;24:219-224.

-54 Tonnessen-Murray CA, Lozano G, Jackson JG: The Regulation of Cellular Functions by the p53 Protein: Cellular Senescence. Cold Spring Harb Perspect Med 2017;7:a026112.

55 Siddiqi S, Sussman MA: The heart: mostly postmitotic or mostly premitotic? Myocyte cell cycle, senescence, and quiescence. Can J Cardiol 2014;30:1270-1278.

-56 Lu Y, Li S, Wu H, Bian Z, Xu J, Gu C, Chen X, Yang D: Beneficial effects of astragaloside IV against angiotensin II-induced mitochondrial dysfunction in rat vascular smooth muscle cells. Int J Mol Med 2015;36:12231232.

-57 Golubovskaya VM, Cance WG: Targeting the p53 pathway. Surg Oncol Clin N Am 2013;22:747-764.

58 Ma S, Zhang H, Sun W, Gong H, Wang Y, Ma C, Wang J, Cao C, Yang X, Tian J, Jiang Y: Hyperhomocysteinemia induces cardiac injury by up-regulation of p53-dependent Noxa and Bax expression through the p53 DNA methylation in ApoE(-/-) mice. Acta Biochim Biophys Sin (Shanghai) 2013;45:391-400.

59 Li L, Hou X, Xu R, Liu C, Tu M: Research review on the pharmacological effects of astragaloside IV. Fundam Clin Pharmacol 2017;31:17-36. 